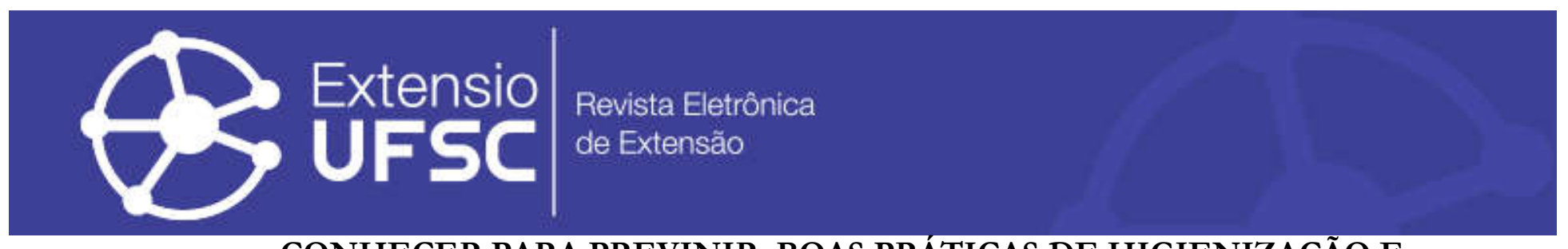

\title{
CONHECER PARA PREVINIR: BOAS PRÁTICAS DE HIGIENIZAÇÃO E MANIPULAÇÃO DE AÇAÍ
}

Klenicy Kazumy de Lima Yamaguchi

Universidade Federal do Amazonas

klenicy@gmail.com

Ana Beatriz Pereira Lelis Costa

Universidade Federal do Amazonas analelisam@gmail.com
Ana Letícia Fonteles Martins Oliveira

Universidade Federal do Amazonas annafontelesoliver@gmail.com

Bianca Kynseng Barbosa da Silva Costa Universidade Federal do Amazonas bianca.costacavalcante@gmail.com

Hudinilson Kendy Lima Yamaguchi Instituto Federal do Amazonas hkendy@gmail.com

Resumo

O açaí tem alto potencial econômico devido ao valor nutritivo e às substâncias bioativas presentes na polpa. No entanto, verifica-se que há riscos que podem comprometer a qualidade do produto alimentício por meio da contaminação resultante da falha na adoção ou manutenção das boas práticas de manipulação. O objetivo deste projeto foi relatar as atividades desenvolvidas em um projeto de extensão sobre as boas práticas na produção da polpa de açaí visando diminuir os riscos de contaminação e esclarecimento sobre a importância e benefícios do Açaí Amazônico. A atividade de extensão foi realizada por acadêmicos do curso de nutrição e biotecnologia do Instituto de Saúde e Biotecnologia da Universidade Federal do Amazonas. Os sujeitos participantes foram 132 alunos matriculados no Ensino Médio (2 ano), do Instituto Federal do Amazonas (IFAM), na cidade de Coari, Amazonas, Brasil. Foi realizada uma palestra, duas oficinas e uma atividade lúdica com os assuntos ministrados. Os resultados demonstraram que o projeto contribuiu com a difusão do conhecimento sobre esse fruto tão importante da região e alertou sobre os principais cuidados com a higienização e sanitização em alimentos, minimizando os riscos de contaminação durante o processamento. Essas abordagens contribuíram para o papel que a universidade representa para a melhoria social, colaborando para o desenvolvimento de seus comunitários.

Palavras-chave: Euterpe. Contaminação de Alimentos. Manipulação. Amazonas.

\section{LEARN TO PREVENT: GOOD MANUFACTURING PRACTICES AND HYGIENE- SANITARY CONDITIONS IN ASSAI}

Abstract

Assai fruit has a high economic potential due to its nutritional value and bioactive compounds in pulp. However, depending on the product being, can occur contamination caused by poor manual handling practices. The aim of this work was to report experience lived on the extension activities carried out by promotion Good manufacturing practice guidelines in assai pulp production in order to prevent contamination risks and show importance and benefits of Amazon assai. The extension activity was carried out by academics from the nutrition and biotechnology course at the Institute of Health and Biotechnology at the Federal University of Amazonas. The subjects were 132 students at high school (2nd year), from the Federal Institute of Amazonas (IFAM), in Coari, Amazon, Brazil. A lecture, two workshops and a ludic activity were realized. Extension project contributed to the knowledge and disseminations whithin about this very important fruit in the region and warned about the main prevent with cleaning and sanitization of food, reducing contamination during processing. These approaches have both contributed to the role of the university in social change contributing with development of their communities.

Keywords: Euterpe. Food Contamination. Manual Handling. Amazon.

\section{SABER PREVENIR: BUENAS PRÁCTICAS PARA LA HIGIENIZACIÓN Y MANIPULACIÓN DE AÇAÍ}

\section{Resumen}

La fruta Açai tiene un alto potencial económico debido a su valor nutricional y compuestos bioactivos en la pulpa. Sin embargo, dependiendo del producto, puede ocurrir contaminación causada por malas prácticas de manejo manual. El objetivo de este proyecto fue informar sobre las actividades realizadas en un proyecto de extensión sobre buenas prácticas en la producción em la açaí pulpa con el fin de reducir los riesgos de contaminación y aclarar la importancia y beneficios del Açaí amazónico. La actividad de extensión fue realizada por académicos del curso de nutrición y biotecnología del Instituto de Salud y Biotecnología de la Universidad Federal de Amazonas. Los sujetos fueron 132 estudiantes de secundaria ( $2^{\circ}$ año), del Instituto Federal de Amazonas (IFAM), en la ciudad de Coari-Amazonas-Brasil. Se realizó una conferencia, dos talleres y una actividad lúdica. El proyecto de extensión contribuyó al conocimiento y la difusión de esta fruta tan importante en la región y advirtió sobre la prevención principal con la limpieza y desinfección de alimentos, reduciendo la contaminación durante el procesamiento. Estos enfoques han contribuido al papel de la universidad en el cambio social, contribuyendo al desarrollo de sus comunidades.

Palavras clave: Euterpe. Contaminación de Alimentos. Manejo Manual. Amazonas. 
Conhecer para previnir: boas práticas de higienização e manipulação de açaí

\section{INTRODUÇÃO}

A região Amazônica abriga a maior floresta tropical do planeta, sendo o berço de espécies frutíferas de interesse comercial. Dentre essa enorme biodiversidade, encontra-se o açaí Amazônico. Esse fruto origina-se de duas espécies de palmeiras, Euterpe oleracea Mart. e Euterpe precatoria Mart., da família Arecaceae, ambas conhecidas popularmente na região como açaizeiro (SCHAUSS, 2010).

O gênero Euterpe possui cerca de 28 espécies localizadas nas Américas Central e do Sul, estando distribuídas por toda bacia Amazônica. As três espécies que ocorrem com maior frequência são E. oleraceae, E. edulis e E. precatoria. No entanto, só duas espécies são exploradas comercialmente na região Amazônica, E. precatoria e E. oleracea (CAVALCANTE, 1996). Ambas apresentam valores nutritivos e compostos bioativos importantes para o organismo humano. $\mathrm{Na}$ colheita, essas espécies podem ser diferenciadas pelas características botânicas, mas, ao serem processadas, são comumente vendidas como açaí (YAMAGUCHI et al., 2015).

O açaí é produzido e comercializado nos estados do Pará, Maranhão, Amapá, Amazonas, Acre e Rondônia (PORTINHO, 2012). Popularmente, na região norte, é consumido como uma bebida energética não alcoólica tradicionalmente denominada de "vinho de açấ", tendo como acompanhamento açúcar, farinha de mandioca, tapioca, camarão ou peixe salgado (Figura 1) (ROGEZ, 2000). A forma de consumo do açaí pode ocorrer de forma distinta dependendo das regiões geográficas, tanto no Brasil quanto no exterior (RABELO, 2012).

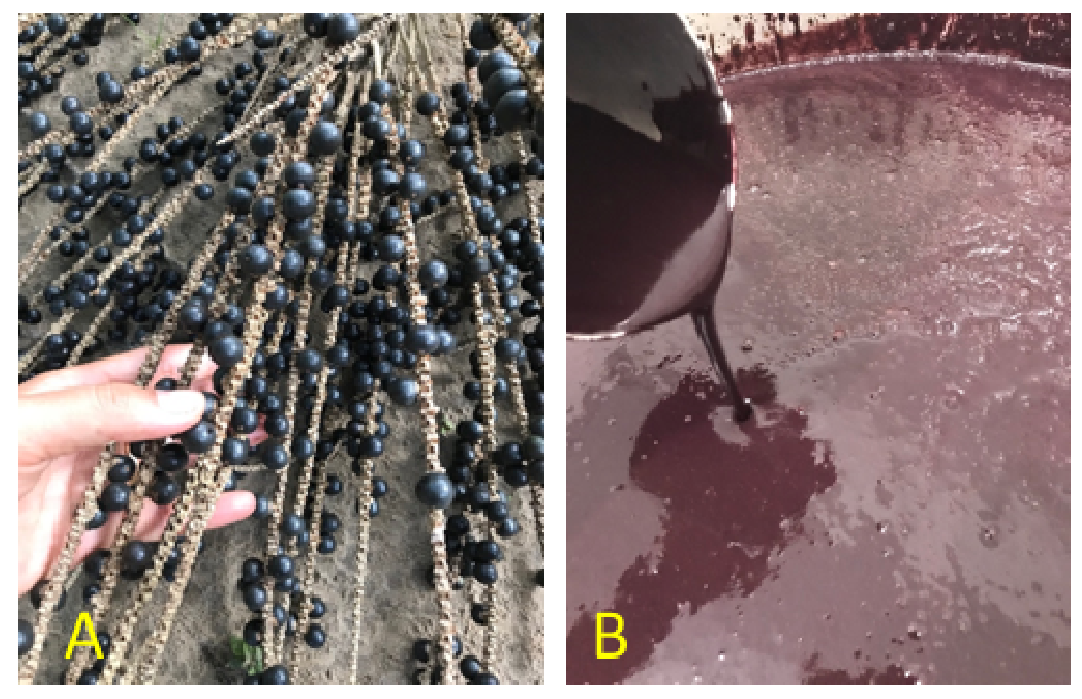

Figura 1 - Açaí Amazônico. A) fruto e B) o "vinho" de açaí. Fonte: Yamaguchi (2019). 
Conhecer para previnir: boas práticas de higienização e manipulação de açaí

O Brasil é o principal produtor, consumidor e exportador do açaí. O interesse por este fruto no mercado nacional e internacional vem aumentando cada vez mais em função do seu alto valor energético, além de apresentar teores consideráveis de fibra alimentar, vitaminas, proteínas, minerais e substâncias bioativas, representadas principalmente pelo elevado teor de antocianinas, que confere a coloração arroxeada, característica do fruto (YAMAGUCHI et al., 2015).

O açaí possui também propriedades nutracêuticas, onde os antioxidantes presentes na polpa atuariam protegendo as células humanas ao combater os processos desencadeados pelos radicais livres, minimizando danos ao DNA e às macromoléculas, que, como consequência, poderiam ocasionar patologias. Em pesquisas realizadas sobre os efeitos biológicos do açaí em modelos celulares e em animais, detectou-se um grande potencial no combate a algumas doenças como câncer, atividade inflamatória e microbiana, prevenção de oxidação de proteínas de baixa densidade (LDL), enfermidades cardiovasculares e doenças neurológicas (MENEZES et al, 2008; YUYAMA et al., 2002; YUYAMA et al, 2011; PORTINHO et al., 2012; YAMAGUCHI et al., 2015).

Estudos de mercado apontam que o aumento da demanda da polpa do fruto é crescente, tornando essa espécie uma alternativa para o desenvolvimento regional e melhoria da qualidade de vida de populações ribeirinhas e da zona rural (IBGE, 2019). O período de frutificação pode ocorrer durante todo o ano, sendo a estação menos chuvosa (julho a dezembro) a que apresenta maior quantidade (CAVALCANTE, 1996; RABELO, 2012).

A polpa de açaí pode ser produzida de maneira artesanal (despejado em uma bacia) ou semi-industrial (com uso da despolpadeira) (OLIVEIRA, CARVALHO e NASCIMENTO, 2000). Contudo, ambas requerem atenção durante a realização de seus processos de extração, pois pode haver alto risco de contaminação durante a manipulação da matéria-prima, desde sua colheita até a obtenção do produto final. Neste sentido, a falta de cuidado e a má higienização no processamento do açaí, seja por meio do manipulador, da fruta ou dos equipamentos, pode representar um risco à saúde da população que o consome, sendo os agentes contaminantes mais comuns as bactérias, fungos e protozoários (COHEN et al., 2011; SANTOS; ROMÃO, 2018; SANTOS; MERLINI, 2010).

Nos últimos anos, houve um aumento considerável no número de casos da doença de Chagas, e constatou-se que sua transmissão acontecia pela ingestão de açaí contaminado pelo protozoário Trypanosoma cruæi, presente no conteúdo intestinal ou fezes do inseto Barbeiro (Triatoma infestans), o vetor da doença de Chagas (CARVALHO, 2018).

Mello e Resende (2018) consideram que as condições higienicossanitárias insatisfatórias (pessoal, ambiental e dos alimentos) provocam a alta contaminação microbiológica das bebidas 
Conhecer para previnir: boas práticas de higienização e manipulação de açaí

de açaí, enfatizando a grande importância da implementação de ações de capacitação para melhor orientar os manipuladores destes produtos.

A obtenção de um açaí seguro para comercialização e, por conseguinte, a prevenção de doenças associadas ao seu consumo passa pela adoção de boas práticas durante a manipulação dos frutos, envolvendo toda cadeia produtiva como: a seleção da matéria-prima, condições seguras de transporte, limpeza do ambiente, equipamentos e utensílios, qualidade da água utilizada, controle de temperatura para armazenamento e higiene pessoal (BEZERRA, 2018).

Há na legislação brasileira regulamentos técnicos e portarias para a fixação dos padrões de identidade e qualidade para a polpa de açaí e do açaí (vinho) que visa estabelecer as qualidades mínimas e os procedimentos higienicossanitários na manipulação e preparo do fruto (BRASIL, 2000). No entanto, essas recomendações nem sempre chegam às populações em geral (CARVALHO, 2018; SANTOS; ROMÃO, 2018).

Dessa forma, torna-se necessário o ensino da gestão da produção que auxilia na divulgação de boas práticas na elaboração e manejo dos frutos, esclarecendo sobre a importância da higienização como um controle de contaminação, diminuindo os riscos aos consumidores, e disseminando os conhecimentos sobre as formas de prevenção.

Assim, ações desenvolvidas pela extensão universitária podem desempenhar um papel fundamental no processo de compartilhamento de conhecimento ao promoverem a disseminação dos estudos acadêmicos na sociedade, produzindo um conhecimento significativo (FERREIRA et al., 2020). As peculiaridades da extensão universitária têm como premissa o desenvolvimento prático, assimilado culturalmente no atendimento das demandas da vida em sociedade, além de viabilizar "o acesso da comunidade aos saberes científicos, filosóficos, culturais e tecnológicos, conferindo um caráter dialógico à relação entre universidade e sociedade" (BORATO et al., 2018, p. 110).

Neste contexto, o projeto de boas práticas de manipulação e higienização do açaí amazônico surge como processo de indissociabilidade entre o ensino, pesquisa e extensão, buscando o fortalecimento das organizações populares a partir da capacitação no sistema em rede, onde o receptor do conhecimento torna-se um agente disseminador deste (CRISOSTIMO; SILVEIRA, 2017). O objetivo deste artigo é relatar as atividades que foram desenvolvidas em um projeto de extensão sobre as boas práticas de higienização e manipulação na produção da polpa de açaí, visando diminuir os riscos de contaminação e esclarecer sobre a importância e benefícios desta fruta. 
Conhecer para previnir: boas práticas de higienização e manipulação de açaí

\section{MATERIAIS E MÉTODOS}

O presente trabalho apresentou uma metodologia com abordagem mista, qualitativa e quantitativa, com caraterísticas de estudo descritivo e caráter exploratório, buscando esclarecer sobre as boas práticas de manipulação e higienização para a produção de açaí, com aplicação dos conceitos teóricos e práticos (GIL, 2018).

A pesquisa ocorreu por meio de um Programa de Atividade Curricular de Extensão (PACE) promovido pelo Instituto de Saúde e Biotecnologia da Universidade Federal do Amazonas (ISB-UFAM) e está inserido no Projeto "Avaliação das diferentes espécies de açaí comercializadas no Médio Solimões", com autorização do Comitê de Ética, CAAE: 97439918.5.1001.5020.

Integraram a equipe os acadêmicos do curso de nutrição e biotecnologia do Instituto de Saúde e Biotecnologia da Universidade Federal do Amazonas (UFAM). Todos os participantes da equipe foram previamente treinados para a padronização das atividades antes da aplicação do projeto. Para tanto, houve práticas no laboratório, apresentação dos tópicos que seriam abordados em aulas expositivas e teste do tempo para execução de cada atividade. Os sujeitos participantes da ação de extensão universitária foram 132 alunos matriculados no Ensino Médio ( $2^{\circ}$ ano), do Instituto Federal do Amazonas (IFAM), na cidade de Coari, Amazonas, Brasil, no segundo semestre de 2019. A amostragem deu-se pela participação de forma voluntária dos discentes após o convite da equipe executora.

As atividades realizadas foram:

a) Palestra: Açaí amazônico

Nesta etapa, ocorreu a apresentação do projeto, dos objetivos e a finalidade com as seguintes temáticas: importância do açaí, formas de extração da polpa (artesanal e mecânica), composição química e atividades biológicas, doenças relacionadas, formas de contaminação do açaí, higienização e boas práticas de manipulação. A exposição durou 60 minutos e ocorreu no auditório do IFAM. Posteriormente, houve um momento de debates, em que os discentes puderam fazer perguntas e esclarecer tópicos da apresentação. Na sequência, os discentes foram divididos em grupos contendo de 15 a 20 estudantes, e encaminhados para as atividades posteriores (2 oficinas e uma atividade lúdica). 
Conhecer para previnir: boas práticas de higienização e manipulação de açaí

b) Oficina 1: Higiene pessoal

Como suporte didático para a oficina, foi elaborado um folder informativo com os procedimentos corretos de higienização das mãos e aplicação prática com: papel toalha, sabonete líquido neutro e álcool em gel.

Os alunos foram direcionados para o laboratório da escola em subgrupos de 14-15 pessoas, e cada um recebeu o folder como guia para a atividade prática. A princípio, houve uma breve explicação sobre a importância das boas práticas de higienização e as implicações geradas quando tal atividade é negligenciada. Em seguida, todos os discentes executaram as etapas de lavagem das mãos, sob supervisão dos acadêmicos de extensão.

Além do processo de lavagem correta das mãos, foram abordados na oficina os momentos indispensáveis em que a atividade deve ser executada (cuidados gerais e as condições higienicossanitárias) e o uso dos utensílios individuais (luva, máscara e touca).

c) Oficina 2: Higiene ambiental e dos alimentos

A segunda oficina constituiu-se das formas de higienização e sanitização em alimentos, evidenciando as especificidades na produção de açaí. Inicialmente, foi realizada a recepção dos discentes e uma breve exposição da importância da limpeza dos alimentos, o uso de materiais sanitizantes, a composição desses materiais e a concentração que deveriam ser utilizadas. Os discentes produziram uma solução com hipoclorito de sódio (água sanitária), lavagem e posterior sanitização de alimentos. Para tanto, utilizou-se hortaliças do cotidiano (tomate, cebola, couve, batata e pimentão). A concentração da solução elaborada seguiu a metodologia recomendada pela ANVISA (8,0 mL/L) (BRASIL, 2004). Explicou-se sobre os passos para produção artesanal do açaí, a importância da temperatura na preparação da polpa e foram trabalhadas também as condições higienicossanitárias que os estabelecimentos deveriam possuir para se manter os padrões de identidade e qualidade (PIQ) do açaí.

d) Atividade lúdica: A trilha da produção do açaí

"Na trilha" é uma atividade lúdica que buscou contribuir para a aprendizagem dos conhecimentos obtidos pelos discentes acerca das temáticas abordadas na palestra e nas oficinas. A atividade ocorreu com a subdivisão em 2 grupos e cada um apresentava um representante. Foram explicadas as regras e estipulado um tempo de 30 segundos para responder cada questão.

Cada equipe jogava o dado e, após a seleção de um número, escolhia uma carta que continha uma questão sobre açaí. Caso acertassem, avançavam nos espaços da trilha, conforme o 
Conhecer para previnir: boas práticas de higienização e manipulação de açaí

número indicado no dado e, se errassem, permaneciam no mesmo local no qual estavam. Ganhava o jogo quem chegasse ao final primeiro.

e) Avaliação

Ao final, os discentes retornaram para o auditório para realizarem a avaliação das atividades desenvolvidas durante a extensão. As perguntas presentes no questionário estão apresentadas na tabela 1. Segundo Gil (2018), pode-se realizar uma análise qualitativa descritiva e observacional sobre a contribuição das atividades para os discentes, e uma análise quantitativa baseadas na aplicação de um questionário que, neste caso, continha 10 perguntas semiestruturadas. Todos os 132 discentes participaram de todas as atividades realizadas.

\section{RESULTADOS E ANÁLISES}

Na região amazônica, o açaí é um fruto amplamente consumido pelos moradores. No entanto, o consumo do produto contaminado pode ocasionar consequências graves para o organismo humano. Uma das principais formas de combater esse quadro relaciona-se ao esclarecimento dos cuidados de higiene e manipulação da polpa desse fruto. Nesse sentido, a escola é um local propício para realização de palestras, oficinas e amplo debate sobre o presente assunto, contribuindo para o desenvolvimento dos sujeitos que poderão disseminar o conhecimento e ampliar as bases teóricas interdisciplinares que a temática propõe.

A aplicação da atividade de extensão ocorreu em um único dia e iniciou-se com a palestra realizada de forma expositiva, com ilustrações e debates. Procurou-se discutir os assuntos relacionados ao açaí, apresentando as duas vertentes, a dos benefícios e a dos malefícios, tentando evitar a polarização, além das características e propriedades do fruto e da composição química (Figura 2).
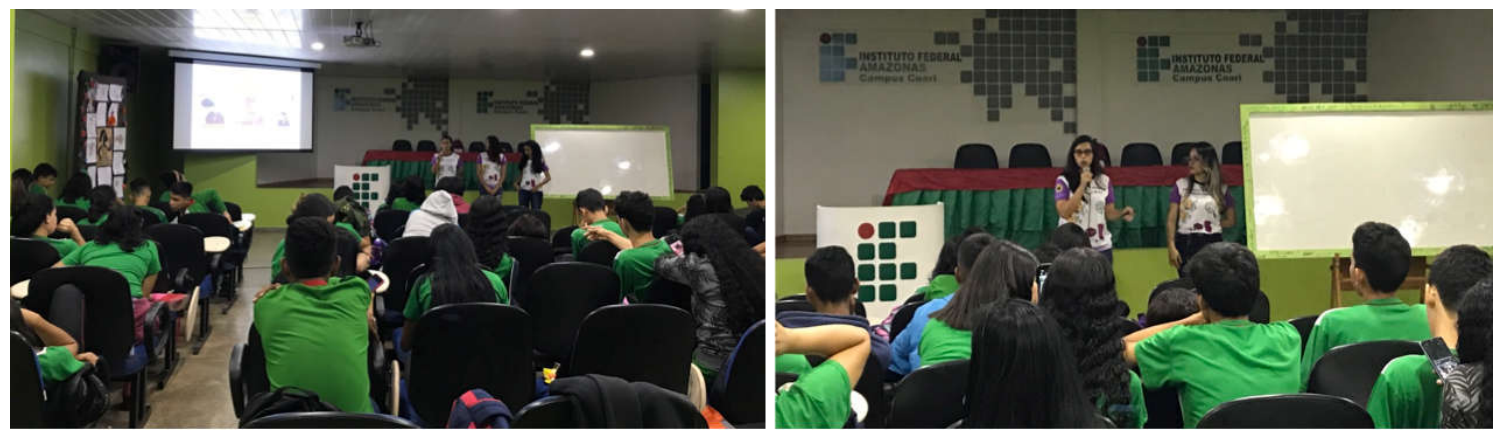

Figura 2 - Palestra sobre o açaí apresentada aos alunos do Ensino Médio (2º ano), do Instituto Federal do Amazonas (IFAM), na cidade de Coari, Amazonas, Brasil, no segundo semestre de 2019.

Fonte: Yamaguchi (2019). 
Conhecer para previnir: boas práticas de higienização e manipulação de açaí

Em sequência, a atividade expositiva ocorreu no formato de circuito e de forma simultânea, contando com a realização de duas oficinas e uma atividade lúdica. Quanto à questão sobre o uso correto da lavagem das mãos, na oficina 1, observou-se a dificuldade dos discentes em termos de conhecimento técnico. Percebeu-se que a maioria dos discentes não sabia sobre as técnicas recomendáveis para higienização das mãos.

No decorrer da atividade, orientados pelos acadêmicos extensionistas, houve uma boa participação dos discentes, gerando conhecimento acerca da importância dessa ação rotineira de higienização que, no entanto, precisa de cuidados básicos para ser eficiente. Puderam-se observar, na Figura 3, as ações desenvolvidas nesta oficina.

Os acadêmicos apresentaram os utensílios que deveriam ser utilizados e a função de cada um, citando o uso de máscara, luva e touca. Após a realização, pôde-se observar a interação entre os discentes e a troca de conhecimento e experiências.
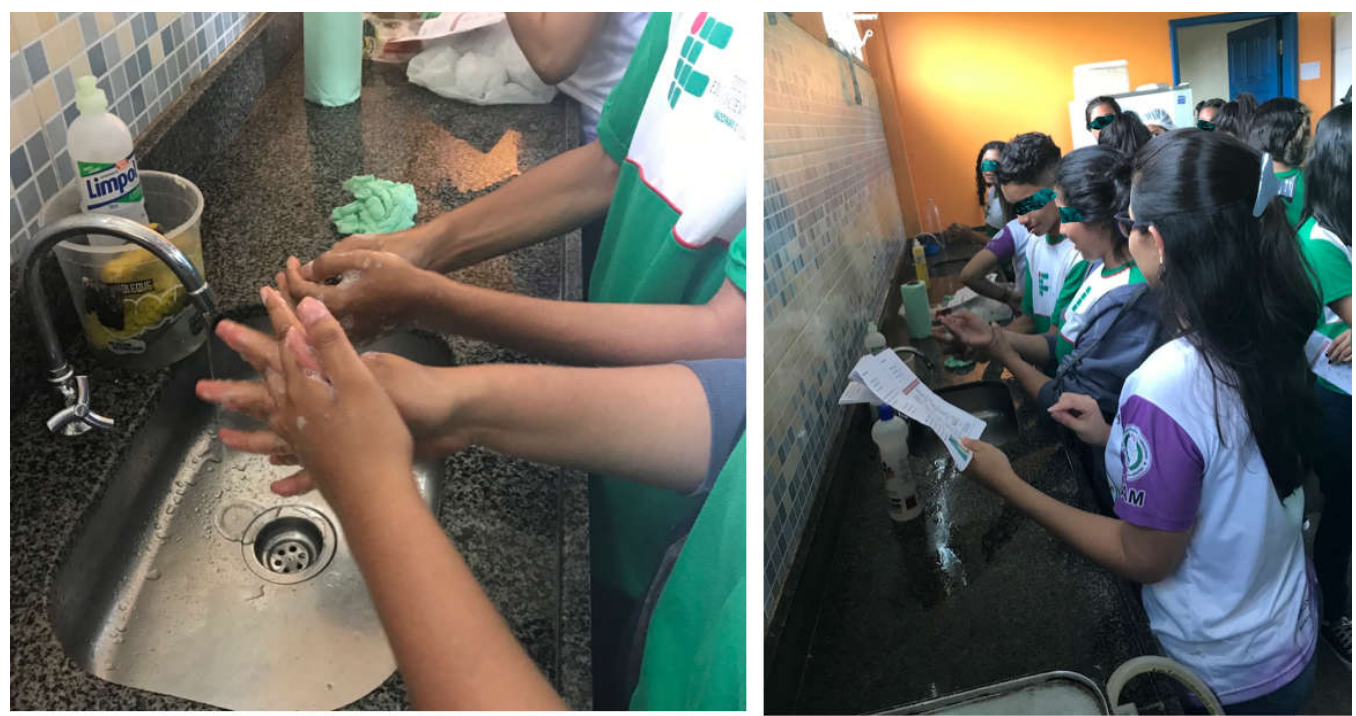

Figura 3 - Oficina 1: Práticas de higienização das mãos proposta aos alunos do Ensino Médio $\left(2^{\circ}\right.$ ano), do Instituto Federal do Amazonas (IFAM), na cidade de Coari, Amazonas, Brasil, no segundo semestre de 2019. Fonte: Yamaguchi (2019).

Na oficina 2, o uso de hortaliças utilizados no cotidiano despertou a atenção dos discentes. As atividades propostas foram: preparação da solução utilizando água destilada e água sanitária, higienização e sanitização, oportunizando ampliar o conhecimento, e aplicar os conceitos para além do fruto açaí.

Embora as práticas de higienização e sanitização devessem ser ações comuns nas residências, alguns discentes afirmaram que conheciam os procedimentos, mas não colocavam em prática. Esse é um aspecto que deve ser evidenciado, pois nem sempre os conhecimentos obtidos em sala de aula perpassam o ambiente escolar. O desenvolvimento da oficina foi positivo 
Conhecer para previnir: boas práticas de higienização e manipulação de açaí

(Figura 4), onde os discentes participaram de forma ativa. Ao final, informaram que entenderam melhor a teoria após a realização da atividade prática.

De acordo com Silva et al. (2015), a capacitação sobre a qualidade higienicossanitária dos alimentos é um dos pré-requisitos para evitar a contaminação, tendo em vista que, a falta de conhecimento ou a negligência é frequentemente uma das causas para a esse cenário e aparecimento de doenças transmitidas por alimentos. Baseado na Organização Mundial da Saúde (OMS, 1989), designa-se de manipulador, qualquer pessoa do serviço de alimentação que entra em contato direto ou indireto com o alimento, sendo essa uma das principais vias contaminantes.

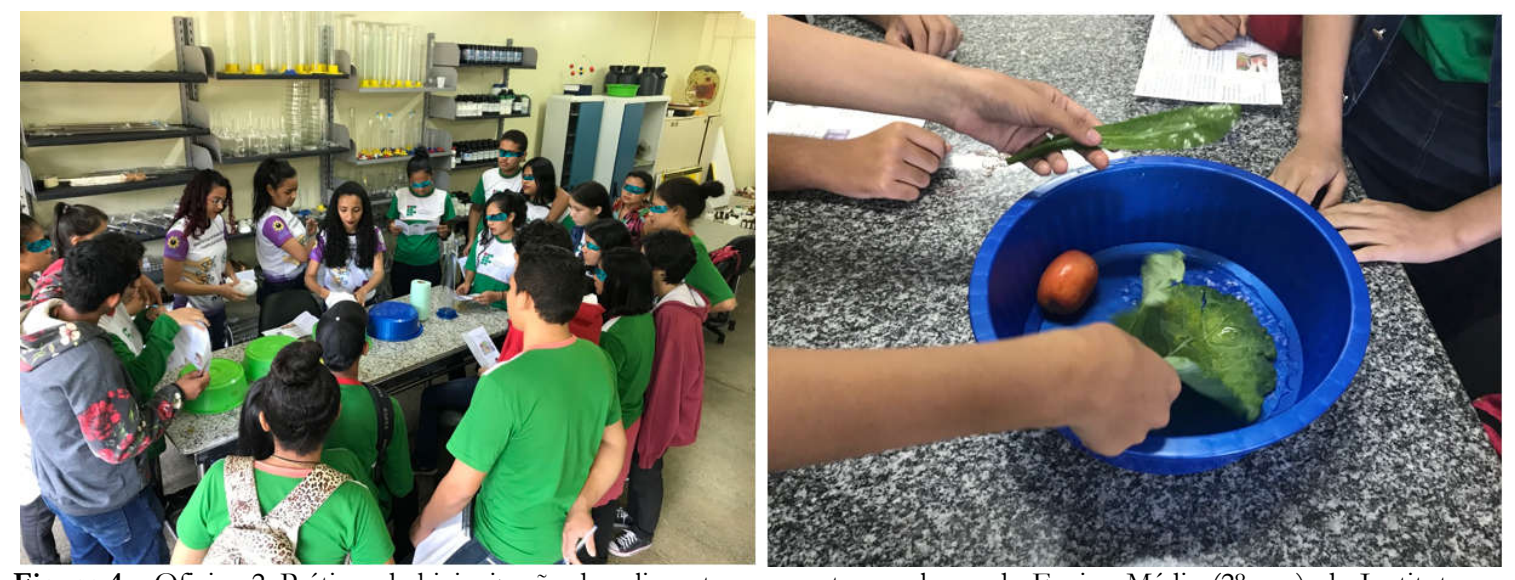

Figura 4 - Oficina 2: Práticas de higienização dos alimentos proposta aos alunos do Ensino Médio (2 ano), do Instituto Federal do Amazonas (IFAM), na cidade de Coari, Amazonas, Brasil, no segundo semestre de 2019.

Fonte: Yamaguchi (2019).

A atividade lúdica (Figura 5) foi atrativa para os alunos. As questões foram bem dinâmicas, baseadas no que eles haviam aprendido na palestra. Se não sabiam, os acadêmicos tentavam auxiliar, esclarecendo os pontos que não ficaram explícitos no decorrer da apresentação. Havia questões sobre como o açaí era produzido; quais as manipulações que deveriam ser usadas pelas pessoas; os benefícios; as doenças causadas por bactérias, protozoários e fungos e os cuidados desde a colheita até o consumo.

A participação dos alunos na atividade foi ótima, destacando a competitividade entre as equipes. Pôde-se observar uma troca de conhecimento e aprendizagem entre os participantes e os acadêmicos universitários. Dessa forma, a ludicidade contribuiu para a integração e o entrosamento dos 2 grupos envolvidos na ação. 

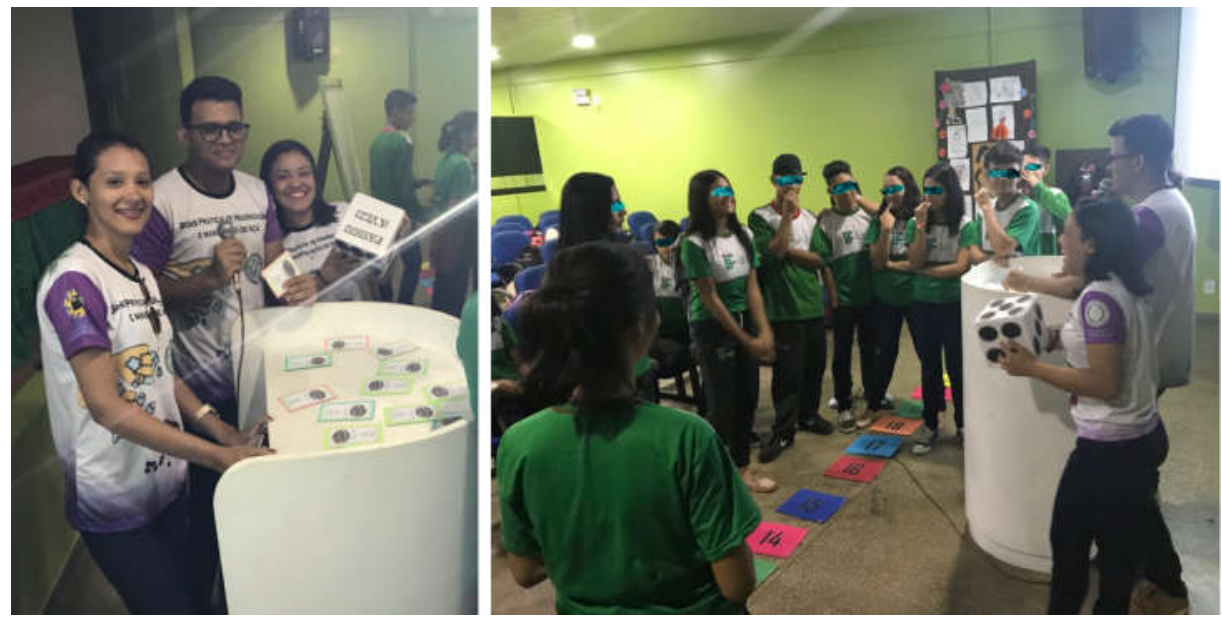

Figura 5 - Atividade lúdica: A trilha da produção de açaí Fonte: Os autores (2019).

Ao final, todos retornaram para o auditório, onde ocorreu a avaliação da atividade. Os discentes perguntaram quando iria ocorrer novamente a atividade de extensão, demonstrando de forma prévia, a aceitabilidade do projeto. As perguntas contidas no questionário foram elaboradas com a finalidade de avaliar as ações realizadas contemplando dados sobre o conhecimento prévio e a avaliação das ações extensionistas. Os resultados obtidos estão expressos na Tabela 1.

Tabela 2 - Avaliação das ações realizadas na atividade de extensão.

\begin{tabular}{|c|c|c|c|}
\hline$n^{\circ}$ & Questão & Opções & Resposta (\%) \\
\hline \multirow[t]{2}{*}{1} & \multirow{2}{*}{$\begin{array}{l}\text { Você sabia antes do projeto sobre as } \\
\text { doenças ocasionadas pela ingestão de } \\
\text { açaí contaminado? }\end{array}$} & $\operatorname{Sim}$ & 38 \\
\hline & & Não & 62 \\
\hline \multirow[t]{2}{*}{2} & \multirow{2}{*}{$\begin{array}{l}\text { Você sabia antes do projeto sobre o que } \\
\text { eram boas práticas de manipulação em } \\
\text { alimentos? }\end{array}$} & Sim & 48 \\
\hline & & Não & 52 \\
\hline \multirow[t]{3}{*}{3} & \multirow{3}{*}{$\begin{array}{l}\text { Quantas espécies de açaí há no } \\
\text { Amazonas? }\end{array}$} & 1 & 9 \\
\hline & & 2 & 91 \\
\hline & & 3 & - \\
\hline 4 & Cite os benefícios de açaí & dissertativa & - \\
\hline \multirow[t]{3}{*}{5} & \multirow{3}{*}{$\begin{array}{l}\text { Quais os organismos que podem causar } \\
\text { doenças por meio do açaí? }\end{array}$} & Fungos & 88 \\
\hline & & Bactérias & 100 \\
\hline & & Protozoários & 100 \\
\hline 6 & $\begin{array}{l}\text { Cite as doenças que podem ser causadas } \\
\text { pela contaminação de açaí }\end{array}$ & Dissertativa & - \\
\hline \multirow[t]{2}{*}{7} & \multirow{2}{*}{$\begin{array}{l}\text { A atividade contribuiu com o } \\
\text { entendimento sobre boas práticas na }\end{array}$} & Sim & 100 \\
\hline & & Não & - \\
\hline
\end{tabular}


Conhecer para previnir: boas práticas de higienização e manipulação de açaí

\begin{tabular}{|c|c|c|c|}
\hline & higienização e manipulação de açaí? & & \\
\hline \multirow[t]{4}{*}{8} & \multirow[t]{4}{*}{ Qual atividade você mais gostou? } & Palestra & 15 \\
\hline & & $\begin{array}{l}\text { Boas práticas de } \\
\text { higienização }\end{array}$ & 22 \\
\hline & & $\begin{array}{l}\text { Oficina de } \\
\text { manipulação de } \\
\text { alimentos }\end{array}$ & 28 \\
\hline & & Atividade lúdica & 35 \\
\hline \multirow[t]{4}{*}{9} & \multirow{4}{*}{$\begin{array}{l}\text { Análise da atividade de extensão } \\
\text { realizada }\end{array}$} & Ótima & 88 \\
\hline & & Boa & 12 \\
\hline & & Regular & - \\
\hline & & Ruim & - \\
\hline \multirow[t]{2}{*}{10} & \multirow{2}{*}{$\begin{array}{l}\text { Você sabe ou conhece alguém que sabe } \\
\text { fazer "vinho de açaí"? }\end{array}$} & $\operatorname{Sim}$ & 71 \\
\hline & & Não & 29 \\
\hline
\end{tabular}

Fonte: elaborado pelas autoras.

$\mathrm{Na}$ questão sobre o conhecimento prévio, apenas 38\% dos estudantes afirmaram que sabiam sobre as doenças ocasionadas pela ingestão de açaí contaminado. Esse dado correlacionase aos $52 \%$ dos participantes que detinham algum conhecimento relacionado às práticas de manipulação em alimentos.

Analisando o entendimento obtido no projeto, 91\% disseram que há duas espécies de açaí comercializadas no Amazonas. No que diz respeito às características desse fruto, sabe-se que no gênero há três espécies frutíferas conhecidas, no entanto, apenas duas são comercializadas como açaí na região norte do Brasil.

Os discentes souberam responder sobre os benefícios (questão 4) e malefícios (questão 6), sendo citadas as atividades antioxidante, anti-inflamatória e a ação energética como os benefícios, e a doença de chagas e infecção intestinal como as principais patologias causadas pela contaminação causada pelos micro-organismos e protozoários. Analisando a atividade, 100\% afirmaram que contribuiu para o esclarecimento do tema (questão 7), sendo que 12\% consideraram "boa" e 68\% consideraram "ótima", ou seja, com unanimidade de aceitação. Dessa forma, o objetivo do projeto foi cumprido.

$\mathrm{Na}$ questão final, $71 \%$ do público alvo afirmaram que sabiam ou conheciam alguém que sabia fazer o "vinho" de açaí. Verifica-se que a inclusão social e o desenvolvimento sócioeconômico-ambiental das comunidades são metas centrais da extensão universitária (BRASIL, 2018). Nesta perspectiva, as ações desenvolvidas neste projeto poderão contribuir para formação dos disseminadores do conhecimento, colaborando de forma significativa para melhoria na oferta 
Conhecer para previnir: boas práticas de higienização e manipulação de açaí

do produto com boas condições higienicossanitárias e redução dos níveis aceitáveis ou eliminação dos riscos de contaminação em alimentos (SANTOS FILHO, 2015).

Segundo Montavão e Barbosa (2020), as atividades extensionistas possibilitam, ainda, ampliar o conhecimento e incentivar o pensamento crítico, o que são fatores importantes para as mudanças sociais e despertam para um conhecimento que visa o desenvolvimento crítico de seus cidadãos.

Trabalhos vêm sendo publicados com a temática açaí, no entanto, diferenciam-se do objetivo deste ao apresentarem pesquisas científicas com interesse farmacológico, químico ou como ferramenta norteadora para disciplinas do ensino regular como Ciências, Biologia e Química (SILVA JUNIOR; SANTOS, 2017; GONÇALVES, 2013). Não foi detectada nenhuma atividade de extensão nas pesquisas bibliográficas disponíveis nas bases de dados brasileiras relacionada a boas práticas de manipulação do açaí, sendo este, pioneiro.

A experiência de extensão universitária apontou um caminho para a integração de conhecimentos e componentes curriculares, tendo como referência as boas práticas de manipulação e higienização do açaí amazônico e promovendo a indissociabilidade entre o ensino, pesquisa e a extensão, uma vez que demandou: a articulação das disciplinas da matriz curricular do curso de licenciatura em Ciências (Biologia e Química), a aplicação das técnicas de boas práticas de manipulação e higienização do açaí amazônico e a possível propagação deste conhecimento para comunidade local.

Apesar das dificuldades intrínsecas à execução das ações de extensão, como a falta de recurso para obtenção de bolsa para os participantes, deslocamento para a instituição receptora, o desenvolvimento deste projeto proporcionou uma experiência gratificante e produtiva, tanto para os alunos do IFAM campus Coari, quanto para a equipe que coordenou a ação, despertando o interesse em contribuir para a propagação das técnicas de boas práticas de manipulação e higienização do açaí amazônico. Desta forma, as técnicas poderão ser apresentadas como referência para outras famílias, já que a produção artesanal desta bebida é bastante difundida.

Os levantamentos de Furtado (2015, p. 73) "estimam que a produção artesanal do açaí é de 470 mil litros por dia", justificando a necessidade de ações desta natureza. Para os acadêmicos universitários, a experiência vivenciada foi enriquecedora, pois puderam compartilhar seus conhecimentos técnicos e científicos relacionados a sua formação universitária. Assim, o projeto atingiu seu objetivo, contribuindo para o fortalecimento do papel social que a universidade apresenta e contribuindo para o desenvolvimento e esclarecimento de seus comunitários. 
Conhecer para previnir: boas práticas de higienização e manipulação de açaí

\section{CONSIDERAÇÕES FINAIS}

Com os resultados deste trabalho, verificou-se a contribuição do projeto relacionada à percepção dos discentes acerca das condições de manipulação e higienização que envolve a produção da polpa de açaí, expandindo os cuidados para os alimentos como um todo.

Notou-se que, embora a temática de higienização seja comum aos discentes, a aplicação dos conhecimentos científicos na manipulação em alimentos era pouco desenvolvida. Houve um aumento da compreensão sobre os cuidados sanitários e as consequências do não cumprimento dessas medidas, estimulando a continuidade desses debates nas escolas, bem como nas cooperativas agrícolas que produzem açaí, e para a comunidade como um todo.

O açaí é uma fruta rica em propriedades biológicas, e o esclarecimento vem como uma estratégia de valorização mercadológica para os produtores e benefícios nutricionais sem riscos de toxinfecções para os consumidores.

Pôde-se apresentar o papel social da universidade em prol do esclarecimento e divulgação do conhecimento científico. Propostas como essas são incentivadas, representando um modo eficiente de esclarecer e prevenir sobre os cuidados na produção da polpa de açaí, além de aproximar os conhecimentos teóricos da prática social.

\section{REFERÊNCIAS}

BEZERRA, V. S. Açaí seguro: choque térmico nos frutos de açaí como recomendação para eliminação do agente causador da doença de Chagas. Macapá: EMBRAPA Amapá, $2018 . \quad$ Disponível em: https://www.embrapa.br/documents/1354337/38742499/Nota+T\%C3\%A9cnica+sobre+o+A $\% \mathrm{C} 3 \% \mathrm{~A} 7 \mathrm{a} \% \mathrm{C} 3 \% \mathrm{AD}+$ Seguro/16cd5b6e-e7a7-9a0c-c79e-7dbdc2701e47. Acesso em: $13 / 4 / 2020$.

BORATO, A.; PEREIRA, M. V. S.; BORDIN, D.; MARTINS, A. S.; FADEL, C. B. Valorização das práticas de ensino, pesquisa e extensão entre concluintes de Odontologia. Revista da ABENO, v. 18, n. 1, p. 103-115, 2018.

BRASIL. Ministério da Educação. Conselho Nacional de Educação (CNE), Câmara de Educação Superior (CES). Resolução n ${ }^{\circ}$ 7, de 18 de dezembro de 2018. Estabelece as diretrizes para a extensão na educação superior brasileira e regimenta o disposto na Meta 12.7 da Lei $n^{\circ}$ 13.005/2014, que aprova o Plano Nacional de Educação - PNE 2014-2024 e dá outras providências. Diário Oficial da União, 19 dez. 2018b, Edição 243, Seção 1, Página 49. Disponível em http://www.in.gov.br/materia//asset_publisher/Kujrw0TzC2Mb/content/id/55877808. Acesso em: 12 jun. 2020. 
Conhecer para previnir: boas práticas de higienização e manipulação de açaí

BRASIL. Ministério da Saúde. Agência Nacional de Vigilância Sanitária. Resolução RDC n 216, de 15 de setembro de 2004. Dispõe sobre o regulamento técnico de boas práticas para serviços de alimentação. Cartilha. Diário Oficial da União. Brasília, DF, 16 set. 2004.

CARVAlHO, G. L. B.; GALDINO, R. S.; CAVAlCANTE, W. M. A.; AQUINO, D. A. Doença de Chagas: sua transmissão através do consumo de açaí. Acta de Ciências e Saúde, v. 1, n. $1, \quad$ p. 1-13, $2018 . \quad$ Disponível em: http://www2.ls.edu.br/actacs/index.php/ACTA/article/view/174. Acesso em: 15/5/2020.

CAVALCANTE, P.B. Edible fruits of Amazonia. 6.ed. Belém: Museu Paraense Emílio Goeldi: CEJUP: CNPq, 1996, 279 pp.

COHEN, K. O.; MATTA, V. M.; FURTADO, A. A. L.; MEDEIROS, N. L.; CHISTÉ, R. C. Contaminantes microbiológicos em polpas de açaí comercializadas na cidade de Belém-PA. Revista Brasileira de Tecnologia Agroindustrial, v. 5, n. 2, p. 524-530, 2011. Doi: 10.3895/S1981-36862011000200004.

CRISOSTIMO, A. L.; SILVEIRA, R. M. C. F. A extensão universitária e a produção do conhecimento: caminhos e intencionalidades. Guarapuava: Unicentro, 2017.

FERREIRA, I. R. C. et al. Saúde bucal na escola: uma experiência extensionista. Extensio: Revista Eletrônica de Extensão, Florianópolis, v. 17, n. 35, p. 126-137, abr. 2020. Doi: 10.5007/1807-0221.2020v17n35p126.

FURTADO, V. Açaí e tecnologia: a indústria popular mais tradicional do Pará se profissionaliza com foco no mercado e na saúde dos consumidores. Revista Amazônia Viva, v. 1, n. 49, p. 3643, 2015.

GIL, A. C. Como elaborar projetos de pesquisa. 6.ed. São Paulo: Atlas, 2018.

GONÇALVES, R. F. O estudo do açaí como estratégia de ensino-aprendizagem e iniciação científica na educação básica, em Belém, Pará. In: XI Congresso Nacional de Educação, p. 30779-30786, 2013. Disponível em: https://educere.bruc.com.br/CD2013/pdf/15140_7093.pdf. Acesso em: 22/5/2020.

IBGE. Instituto Brasileiro de Geografia e Estatística. Produção e extração vegetal e silvicultura, 2019. Disponível em: https://sidra.ibge.gov.br/tabela/289 Acesso em: 10/6/2020.

MELLO, C. N.; RESENDE, J. C. P. Avaliação microbiológica de vitaminas de açaí comercializadas na região do Barreiro, Minas Gerais. Sinapse Múltipla, v.7, n.1, p. 27-37, 2018.

MENEZES, E. M. S.; TORRES, A. T.; SABAA SRUR, A. U. Valor nutricional da polpa de açaí (Euterpe oleracea Mart) liofilizada. Acta Amazônica, v. 38, n. 2, p. 311-316, $2008 . \quad$ Doi: 10.1590/S0044-59672008000200014.

MONTALVÃO, D. M.; BARBOSA, H. D. A. Educação patrimonial com adolescentes de bairros periféricos de Belém do Pará como estratégia de valorização da memória cultural. Extensio: Revista Eletrônica de Extensão, Florianópolis, v. 17, n. 35, p. 19-39, 2020. Doi: 10.5007/1807-0221.2020v17n35p19.

OLIVEIRA, M S. P.; CARVALHO, J. E. U.; NASCIMENTO, W. M. O. Açaí (Euterpe oleracea Mart.). Série frutas nativas, 7, Jaboticabal: FUNEP, 2000, 52p. 
Conhecer para previnir: boas práticas de higienização e manipulação de açaí

OMS. Organização Mundial da Saúde. Métodos de vigilância sanitária y gestión para manipuladores de alimento: informe de uma reunión de consulta de la OMS. Genebra: OMS, 1989.

PORTINHO, J. A.; ZIMMERMANN, L. M.; BRUCK, M. R. Efeitos benéficos do açaí. International Journal of Nutrology, v. 5, n. 1, p. 15-20, 2012. Disponível em: http://www.medicinabiomolecular.com.br/biblioteca/pdfs/Fitoterapia/fi-0429.pdf. Acesso em: 10/4/2020.

RABELO, A. Frutos nativos da Amazônia: comercializados nas feiras de Manaus-AM. Manaus: INPA, 2012. 372p.

ROGEZ, H. Açaí: preparo, composição e melhoramento da conservação. Belém: UDUPA, 2000. 360pp.

SANTOS FILHO, J. S. Condições higiênico-sanitárias do processo de obtenção artesanal de açaí no município de Macapá - AP. 2015. 74 f. Dissertação (Mestrado Profissional em Vigilância Sanitária)- Instituto Nacional de Controle de Qualidade em Saúde, Fundação Oswaldo Cruz, Macapá, 2015.

SANTOS, F. N.; ROMÃO, N. F. Avaliação microbiológica e parasitológica de polpas de açaí comercializadas na cidade de Ji-Paraná-RO. SaBios-Revista de Saúde e Biologia, v. 12, n. 2, p. 27-32, 2018. Disponível em: http://revista2.grupointegrado.br/revista/index.php/sabios2/article/view/2405. Acesso em: 20/3/2020.

SANTOS, S. A.; MERLINI, L. S. Prevalência de enteroparasitoses na população do município de Maria Helena, Paraná. Ciência \& Saúde Coletiva, v. 15, n. 3, p. 899-905, 2010 . Doi: 10.1590/S1413-81232010000300033.

SCHAUSS, A. G. Acai (Euterpe oleracea Mart.): a macro and nutrient rich palm fruit from the Amazon rain forest with demonstrated bioactivities in vitro and in vivo. In: D. R. Watson \& V. R. Preedy, Bioact foods promot health, Oxford: Academic Press, pp. 479-490, 2010. Doi: 10.1016/B978-0-12-374628-3.00032-3.

SILVA, A. A.; BASSANI, L.; RIELLA, C. O.; ANTUNES, M. T. Manipulação de alimentos em uma cozinha hospitalar: ênfase na segurança dos alimentos. Caderno pedagógico, Lajeado, v. 12, n. 1, p. 111-123, 2015.

SILVA JUNIOR, C. N.; SANTOS, V. S. Açaí como contexto para uma aula de bioquímica na educação de jovens e adultos da Amazônia. In: X Congresso Internacional sobre investigacion em didactica de las Ciencias: ensenanza de las ciencias, n. extraordinário, p. 4093-4099. 2017.

YAMAGUCHI, K. K. L.; LIMA, E. S.; PEREIRA, L. F. R.; LAMARÃO, C. V.; VEIGA JÚNIOR, V. F. Amazon acai: chemistry and biological activities: a review. Food Chemistry, v. 179, p. 137-151, 2015.

YUYAMA, L. K. O.; AGUIAR, J. P. L.; SILVA FILHO, D. F.; YUYAMA, K.; VAREJÃO, M. J.; FÁVARO, D. I. T.; VASCONCELlOS, M. B. A.; PIMENTEL, S. A.; CARUSO, M. S. F. Caracterização físico-química do suco de açaí de Euterpe precatoria de diferentes ecossistemas 
Conhecer para previnir: boas práticas de higienização e manipulação de açaí

amazônicos. Acta Amazônica, v. 41, n. 4, p. 545-552, 2011. Doi: 10.1590/S004459672011000400011.

YUYAMA, L. K. O.; ROSA, R. D.; AGUIAR, J. P. L.; NAGAHAMA, D.; ALENCAR, F. H.; YUYAMA, K.; CORDEIRO W. O.; MARQUES, H. O. Açaí (Euterpe oleracea Mart.) e CamuCamu (Myrciaria dubia (H.B.K.) Mc Vaugh) possuem ação anti-anêmica? Acta Amazônica, v. 32, n.4, p. 625-633, 2002.

Recebido em: 13/06/2020

Aceito em: 13/04/2021 